\title{
Mi encuentro con los jesuitas
}

Mi primer encuentro con los jesuitas ocurrió cuando estudiaba secundaria en un pequeño pueblo del nororiente del país. De ello, ciertamente, hace muchísimo tiempo. Quién sabe por qué razones, llegó de visita a nuestro centro de estudio un sacerdote jesuita y nos reunieron a todos los estudiantes para escucharlo. El jesuita, de mediana edad, no impartió una charla, sino que nos pidió que le presentáramos por escrito cualquier pregunta que se nos ocurriera y él, las contestaría. No recuerdo qué le pregunté, pero sí me impresionó lo mucho que sabía.

Con Chungo, uno de mis mejores compañeros, luego de una pequeña reflexión acerca de la sapiencia del jesuita, nos fuimos a buscarlo al convento y le manifestamos nuestro deseo de hacernos jesuitas, sin confesarle, obviamente, que para lograr saber tanto como él. A mí me preocupaba que mis padres no eran casados y que a lo mejor por eso no me aceptarían. Entonces, le pregunté que si eso no era un obstáculo y él me manifestó: "No, siempre que el muchacho prometa, es posible hallar una salida". Corrí entusiasmado a pedir permiso a mi papá, pero éste me salió muy enojado, diciéndome que si él quería que yo estudiara, era para que después ayudara a mis hermanos menores, que nosotros éramos pobres, etc. Como se observa, el factor económico juega un papel mucho más determinante de lo que se cree, al punto que acabó con mi "vocación jesuítica". Sin embargo, siempre que inicio un curso les digo a los estudiantes: "Pregunten lo que quieran, no teman avergonzarme, lo peor que puede ocurrir es que no sepa la respuesta". (En mis adentros me digo, al fin y al cabo, yo no soy como aquel sacerdote jesuita de mi adolecencia.)

Mi segundo encuentro con los jesuitas ocurrió cuando ya entrado en años y luego de recorrer algo de mundo, vine a estudiar a la UCA. En aquella época la llamaban "La femenina", pero recordaba que cuando había estudiado derecho había tenido compañeros provenientes del Liceo, del Externado, del Instituto Nacional, etc., y los del Externado, al menos durante el primer año, nos superaban a todos nosotros y recordaba a aquel padre jesuita que había llegado a Ilobasco entre 1957 y 1959, pues no recuerdo exactamente el año.

De esta segunda época -que a su vez tiene varias fases, la de estudiante y la de profesor, la cual a su vez se divide en antes y después del martirio de los padres- recuerdo varias anécdotas. Una de ellas está relacionada con el padre Jalón, quien nos daba clase de sociología y quien, en cierta ocasión, cuando le fui a prestar un libro para estudiar marxismo, me entregó uno de propaganda anti-comunista, aunque con la apariencia de ser muy "científico". A los pocos días se lo devolví, pero como él tenía una de las mejores bibliotecas sobre marxismo, le pedí que me permitiera escoger, porque el libro que me había prestado no era lo que yo quería. No sin refunfuñar, terminó accediendo a mi petición, y con sus libros comencé a estudiar a Marx en las propias fuentes. Contaban, no sé si sería cierto, que como el padre Jalón pretendía refutar a Marx, leía mucho sus obras, no sé si al fin logró su objetivo. 
Otra anécdota está relacionada con el padre Ibisate, mi profesor de macroeconomía. En cierta ocasión, me puso un diez en un examen. Yo sabía que no me lo merecía. De modo que en el siguiente examen le puse unas líneas en las cuales le decía que no me agradaba que me regalaran la nota y que si no me había ganado el diez, él no tenía por qué ponérmelo. Al devolverme el examen corregido me encontré, no sin sorpresa, con toda una página escrita a máquina, en la cual me explicaba las razones que él había tenido para evaluarme en la forma en que lo había hecho y nuevamente, me ponía diez. Su carta, durante muchos años, estuvo pegada en una de las paredes de madera de mi estudio. La aprecié tanto que en más de alguna ocasión manifesté que si no obtenía el título, por las razones que fueran, esa carta del decano sería mi título. De él aprendí, además, lo valioso que es el tiempo de clase, al punto que a él no le agradaba que le hiciéramos preguntas, particularmente, preguntas necias.

Hay una anecdota cuyo protagonista es el pa- dre Gondra. Al principio, el padre Gondra me veía como la personificación del comunismo, al punto que habiéndonos autorizado para poner un periódico mural de la naciente organización estudiantil que habíamos creado - no era el FUR-30, por cierto-, nos lo mandó quitar. Lo colocamos un sábado por la tarde, pero el domingo ya no amaneció. Siguió de cerca a nuestra organización y cuando después de un año de haber sido los representantes de ciencias económicas, perdimos la re-elección por una mínima diferencia, se indignó con aquellos que no habían votado por nosotros. Creo que me llegó a apreciar, porque en cierta ocasión que le fui a pedir que me aumentara la cuota estudiantil, me dijo que no, porque ya vendría un aumento y saldría perjudicado. Quienes conocieron cómo el padre Gondra cuidaba los centavos, estarán de acuerdo en que realmente llegó a apreciarme.

$\mathrm{El}$ año en que fui representante estudiantil de nuestra facultad fue muy rico en anécdotas. Una inolvidable con el padre Nacho, fue la siguiente.

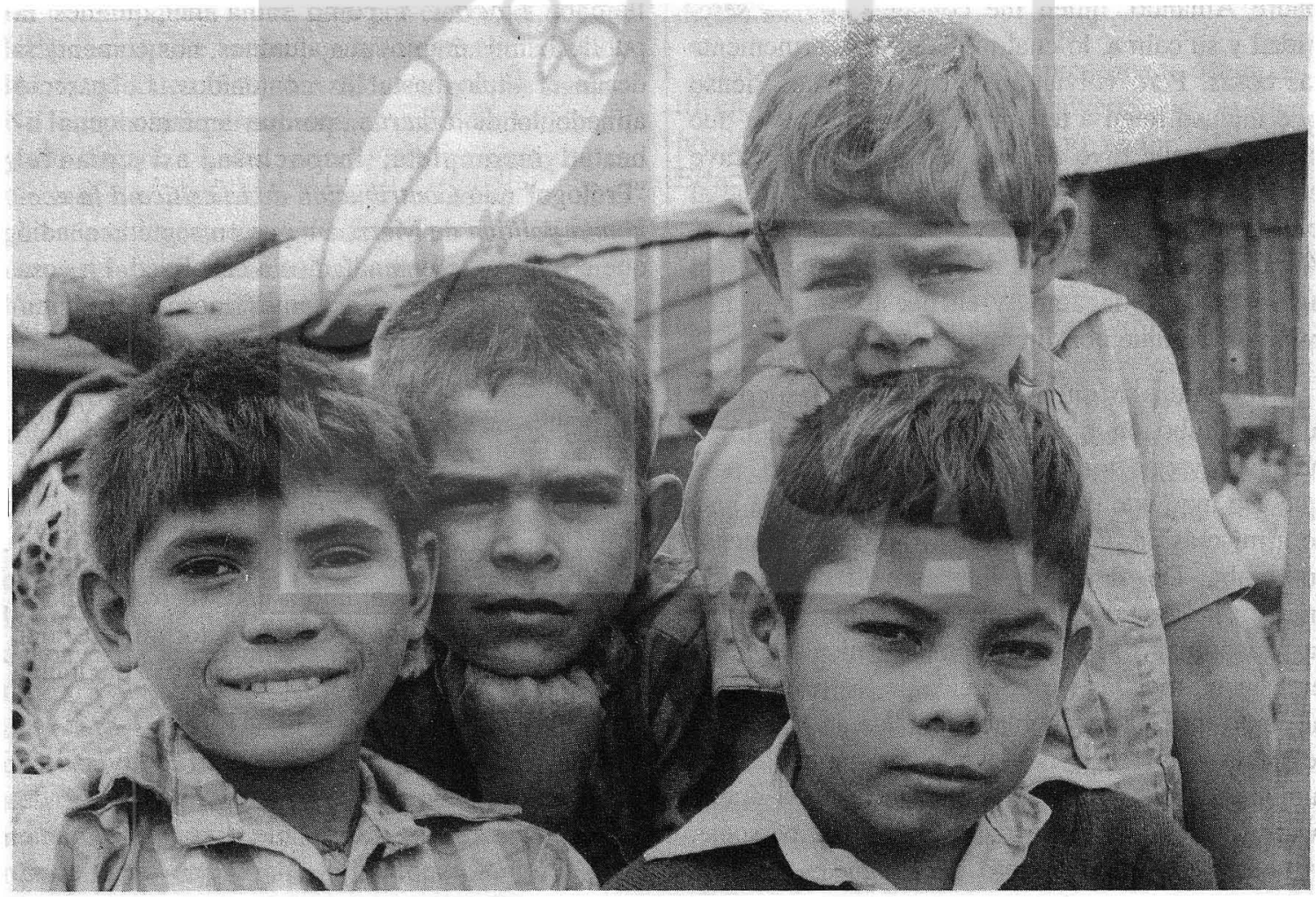


Los directivos de la sociedad de estudiantes fuimos convocados por el padre Nacho y por el decano de estudiantes, Héctor Oquelí, para discutir un problema estudiantil. Nos reunimos en la segunda planta de la biblioteca. No habíamos comenzado la reunión cuando el padre Nacho me dijo, "pero mirá Aquiles, según tengo entendido, tú eres un fracasado". Mis compañeros se quedaron fríos, ya que el acuerdo era que sólo yo iba a hablar y conocían mi carácter explosivo. Sin embargo, yo conocía a Héctor, ya que habíamos sido compañeros en la facultad de derecho y sabía que el padre Nacho era psicólogo. De modo que con la mayor tranquilidad le manifesté: ésa es su opinión, pero con todo, no hemos venido a discutir éso. Salimos felices de la reunión.

Creo que con el tiempo se dio cuenta que había sido mal informado, ya que en una disputa que tuve con la encargada del departamento de economía, obviamente, cuando ya trabajaba como profesor, terminó dándome la razón, cosa inusual. Pero adicionalmente y en honor a la verdad, debo agregar que en la polémica fui asesorado por el padre Amando, quien me contagió con su serenidad y su calma, lo cual me facilitó enormemente las cosas. Pero volviendo al padre Nacho. Pienso que incluso llegó a tenerme algún aprecio, ya que cierta vez que tuve una fisura en un pie y estuve enyesado, se tomó la molestia de ir a visitarme al cubículo, siendo como ya era el vicerrector. Aunque nunca hablamos del incidente, pienso que ambos lo recordábamos y en nuestro interior nos reíamos, aunque por diferentes razones.

Del padre Montes recuerdo muchas cosas, aunque hubo un mal entendido que nunca logré aclararle y que me hubiera gustado hacerlo, porque eso hizo que durante algún tiempo pasara junto a mí más erguido de lo que normalmente acostumbraba. De él pienso que aprendí, aunque de manera indirecta, ya que nunca trabajamos juntos, las ganas por la investigación. Lo mismo que su entusiasmo por las experiencias de los refugiados, al punto que cuando hablaba de ellas, la mirada se le hacía más fuerte de lo que normalmente era, aunque yo en aquel momento tenía serias dudas acerca de lo que ocurriría cuando esas personas volvieran al país, al punto que llegué a sostener que eran "experiencias en invernadero". Paradójicamente, he dedicado los últimos tres años de mi vida a conocerlas y a escribir sobre las mismas.

Pero un año antes había tenido el contacto con los jesuitas que habría de transformar mi vida de adulto, tuve de profesor al padre Ellacuría. Creo que fue en Filosofía II ó en Etica, no lo recuerdo muy bien. La cosa es que volví a experimentar aquella sensación que tuve cuando adolecente, la necesidad de saber, pero ya no el saber por el saber mismo, sino que ahora se trataba de un saber referido a la realidad. Aprendí muchas cosas -de las cuales no me ocuparé ya que no es esa la intencionalidad de estas líneas-, por ejemplo, que a muchas preguntas, la respuesta que hay que dar primero es depende, de que la teoría hay que traerla a la realidad, él siempre la actualizaba y eso me caló muy hondo. Así como su insistencia en conocer la realidad. Y su clásica pregunta, ¿para qué es importante conocer la realidad? Al menos, para ver si así les da gana de cambiarla, se respondía, medio en serio, medio en broma. El padre Ellacuría leía nuestra publicación que se llamaba Libert... Y como sabía que quienes la publicábamos éramos sus alumnos, nos comentaba desde el título hasta los contenidos. Le pareció atinado lo de Libert..., porque teníamos una libertad incompleta, inconclusa, así como el "Prólogo" a la Contribución de la crítica a la economía política de Marx, aunque en seguida añadió que a saber si lo entendíamos a cabalidad. La cosa es que nosotros nos sentíamos motivados, entusiasmados e identificados con su pensamiento. $\mathrm{Al}$ punto que un día de tantos, lo invitamos a que nos diera una charla un sábado por la tarde. Y nos expuso lo que el denominaba: "El socialismo latinoamericano". No sé por qué razón no siguió trabajando esta temática o si dejó algo escrito sobre ella. Lo que sí recuerdo es que los "revolucionarios" de aquella época, uno a uno, fueron abandonando el aula, cuando comenzó a formularse una serie de preguntas concretas respecto a la lucha guerrillera y sus posibilidades de éxito.

Desde entonces procuré asistir a todas las clases que el padre impartía, sin ser estudiante de filosofía. En cierta ocasión me dijo: "usted tiene que estudiar escolástica, para que aprenda a 
ordenar su pensamiento. Aunque lo mejor sería que estudiara la carrera de filosofía". En otra ocasión, cuando vio que no había aceptado su sugerencia de estudiar filosofía, me dijo "¿usted sabe quién es el ministro de industria en Nicaragua?". "No sé, padre", le respondí. "Un filósofo", me dijo. "¿Pero sabe quién ha sido el mejor Ministro de Educación que ha tenido El Salvador?". "Samayoa", le respondí. "Un filósofo", añadió. En cierta ocasión, cuando iniciaba un curso, me dijo: "usted cree que vamos a estudiar a Hegel, pero no. Hoy nos vamos a ocupar de Dios". El sabía que yo andaba queriendo estudiar a Hegel para, según dicen, mejor entender a Marx. La cosa es que terminé matriculándome en la carrera de filosofía, aunque nunca llegué a terminarla.

En otra ocasión, cuando ya era profesor y comenzaba a dar el paso de dejar los manuales y enseñar economía política, a partir de El capital de Marx, llegué todo atormentado a platicar con él sobre lo difícil que me estaba resultando y lo mal que me sentía por no poder ser un excelente profesor, pero él me dijo: "quien escribe las obras las domina quizá en un cien por ciento, el que las lee y las expone en un porcentaje mucho menor y los estudiantes, asimilan todavía mucho menos. No hay por qué perturbarse, es cuestión de tiempo, ya lo llegará a hacer mejor". Salí tranquilo de su oficina. Lo que nunca supe es cómo se las arreglaba para tener tiempo hasta para escucharle a uno sus lamentos, lo cual siempre me pareció muy humano de su parte, aunque creo que es una práctica muy difícil de imitar.

Pero mis lamentos respondían a que en ese entonces yo deseaba prepararme más, e incluso a una carta de la Junta de Directores en la que me comunicaban un aumento de sueldo, respondí que no necesitaba el aumento, que lo que quería era que me otorgaran una beca. Quizá esta haya sido la única vez en que un rector no me ha respondido a una carta. $Y$ lo digo sin pedantería, como una muestra del trato que he recibido en la UCA. Sin embargo, cuando decidí, tiempo después, conseguir la beca por mis medios y propuse a las autoridades, al padre Ellacuría en particular, que me concedieran medio sueldo, porque la beca obtenida no era familiar, le pareció racional y justo, dadas las limitaciones presupuestarias por las que atravesaba la universidad. Así me fui contento a sacar mi maestría.

Una sensación que siempre tuve con el padre Ellacuría es que él era quien mandaba y no me refiero a la época cuando fue rector de la universidad, sino antes. Por ejemplo, cuando la UCA celebró un evento denominado "La UCA diez años después", no se por qué razón, estando en tercer año, se me pidió que comentara la ponencia del rector Román Mayorga. Con su modo de hablar sonriente, el rector dijo: "yo tengo la ventaja de conocer de antemano los comentarios que van a hacer a mi ponencia, de modo que de una vez, voy aprovechar para darles respuesta". A mí, aquéllo no dejó de molestarme, me levanté de mi sitio con mucho cuidado, me acerqué donde el padre Ellacuría y le dije: "padre, si él está cambiando su ponencia, ¿puedo también cambiar mi comentario?". "Sí, hazlo", fue su respuesta. Y como si hubiese recibido autorización para atacar, subí al estrado y dije tales cosas que en el receso, si Román no agarra a su mujer, tendría las huellas de sus uñas en mi cara.

En otra ocasión, siendo representante estudiantil en el Consejo Superior Universitario, el cual presidía Román Mayorga como rector, el padre Ellacuría sostenía la tesis de que había que expulsar de la UCA a algunos de los estudiantes del FUR-30, por unos incidentes que habían ocurrido a raíz de su absurda demanda de no seleccionar a los estudiantes de nuevo ingreso. Todos parecían estar de acuerdo, menos yo, que tenía la obligación de defenderlos por ser su representante. Sostuve, entre otras cosas, que la situación que se había dado, no estaba reglamentada y recordé aquel aforismo jurídico de mis años de estudiante de derecho nulla crimen sine laege, al cual el Dr. Ungo le dio respuesta. Pero luego vi que el padre Ellacuría suavizó su posición y el resto, que hacía un momento clamaba por la expulsión definitiva, también flexibilizó su posición. En ese momento, el tema del debate ya no era la expulsión definitiva, sino el número de años de suspensión. Entonces, tomé una actitud osada e irreverente, pues a mí me pareció que el padre Ellacuría era quien en realidad mandaba. 
Para descontrolar a los miembros del Consejo Superior Universitario, les dije: "lo que pasa es que aquí todos bailan el son que les toca el padre Ellacuría...". No sé, si alguno de aquellos estudiantes suspendidos y luego convertidos en guerrilleros se ha reincorporado a la UCA, pero si alguno lo hizo, fue por mi creencia en que el padre Ellacuría era quien mandaba. $Y$ es que con su racionalidad increíble, convencía y generaba esa sensación de autoridad.

Algo semejante experimenté, cuando se iba emitir un pronunciamiento para apoyar el proceso de transformación agraria de Molina. En la reunión del Consejo Superior Universitario, fui el único que votó en contra, porque en esa época creía que ese proyecto mediatizaría el proceso revolucionario en ciernes. Algunos, indignados porque me resistía a alinearme, propusieron que razonara mi voto en contra. Les respondí que estaba dispuesto a hacerlo, siempre y cuando primero lo hicieran todos los que habían votado a favor. Suponía que varios iban a decir disparates que iban a ser útiles para justificar mi voto en contra. El padre Ellacuría, que no presidía el Consejo Superior Universitario, le susurró a Román, quien era el rector, que no era necesario y así se hizo. Supongo que él descubrió inmediatamente cuál era mi "jugada".

Para mí, el padre Ellacuría fue como aquel jesuita que en mis años de inocente juventud creí que lo sabía todo y me suscitó el deseo de ingresar a la Compañía, con la diferencia que cuando conocí al padre Ellacuría ya era un adulto. El me generó el deseo de abandonar un trabajo bastante bien remunerado y dedicar mi vida a la UCA, porque comprendí que aquí podía realizarme como profesional y como ser humano, y a su vez servir a los pobres, convicción que tuve desde muy joven y que luego adquirió sentido racional a través del marxismo. Esa convicción, lenta e impercepti- blemente, se fue potenciando con las visiones ellacurianas.

Creo, no sé si estoy equivocado, que durante el rectorado del padre Ellacuría fue cuando los profesores de la UCA estuvimos peor pagados. En aquellos años pesaba la deuda con el BID. Pero él, con toda tranquilidad, cuando tímidamente insinuábamos algo respecto a los salarios, nos respondía, "yo no sé para qué quieren ganar más, hay que vivir con austeridad". En otras ocasiones comentaba, bromeando, "el trabajar en la UCA es un privilegio, ustedes deberían de pagar por trabajar aquî'. Y a los miembros del departamento de economía nos manifestó, más o menos, lo siguiente: "yo entiendo que necesitan ganar más. Desafortunadamente, más del 10 por ciento no les podemos aumentar. E imagino que ustedes tampoco desean cualquier dinero, porque la AID nos ha venido a ofrecer dinero, pero yo les he dicho que no".

$\mathrm{Y}$ aunque parezca mentira, los que nos hemos sentido realmente identificados con la UCA y no la hemos considerado tan sólo como un trampolín para formarnos o escalar posiciones mejor remuneradas, o como un simple lugar donde obtener algún ingreso, trabajábamos con ganas, con entusiasmo, con mística, porque nos sentíamos parte de una cosa mayor, de un proyecto muy importante, el ser "la universidad para el cambio social". Al punto que luego de su desaparición física, junto a sus otros excelentes compañeros y las dos trabajadoras, personalmente, me hice una promesa: conservarme fiel al ideario de la UCA y procurar rendir más de lo que antes rendía, dentro de mis limitaciones, por supuesto. Creo, que eso me habría respondido el padre Ellacuría, si le hubiese preguntado, ¿qué debemos hacer ahora que ustedes ya no están? 